\title{
Secondary failure of nasal intermittent positive pressure ventilation using the Monnal D: effects of changing ventilator
}

\author{
Ian E Smith, John M Shneerson
}

\begin{abstract}
Background - Some patients started on nasal intermittent positive pressure ventilation (NIPPV) with the Monnal D ventilator deteriorate after a period. The effects of changing them to the Nippy ventilator were investigated.

Methods - The records of such patients were examined retrospectively. Comparisons were made between blood gas tensions and overnight oximetry records before NIPPV, 12 weeks after the initiation of NIPPV with the Monnal D, at the time of deterioration, and 12 weeks after initiation of treatment with the Nippy ventilator.
\end{abstract}

Results - Ten patients (seven women) were identified. Prior to starting NIPPV their mean (SD) age was $59.6(8.39)$ years and their mean arterial oxygen and carbon dioxide tensions $\left(\mathrm{PaO}_{2}\right.$ and $\left.\mathrm{PaCO}_{2}\right)$ while breathing air were 6.1 (1.79) and 9.6 (3.28) $\mathrm{kPa}$, respectively. All were started on NIPPV with the Monnal D with improvements in symptoms, $\mathrm{PaO}_{2}, \mathrm{PaCO}_{2}$, and overnight oximetry after 12 weeks of treatment. After a mean interval of 118 (69.0) weeks all measures of ventilation had deteriorated and the patients were converted to the Nippy ventilator. Twelve weeks after initiation of treatment with the Nippy ventilator symptoms and overnight oximetry were improved again and the mean $\mathrm{PaO}_{2}$ and $\mathrm{PaCO}_{2}$ were 8.9 (1.27) and 6.9 $(0.45) \mathrm{kPa}$, respectively. After a total mean period of 59 (26.9) weeks on the Nippy all but one of the patients have maintained this improvement.

Conclusions - Support with NIPPV using the Monnal $D$ ventilator may fail after an interval and changing to the Nippy ventilator can reverse this deterioration, probably because of its superior responsiveness to leaks and patient effort. The regular follow up of patients on long term NIPPV is necessary if secondary treatment failure is to be identified and effectively treated. (Thorax 1997;52:89-91)

Keywords: nasal intermittent positive pressure ventilation (NIPPV), Monnal D ventilator, Nippy ventilator.
The Monnal D is among the most widely used home ventilators with worldwide sales in excess of 10000 units (Taema Ltd, Paris, France). Between 1988 and 1993 we started 112 patients on long term nasal intermittent positive pressure ventilation (NIPPV) using the Monnal D. Most initially responded well to treatment but a number have since deteriorated. The aim of the present investigation was to examine the effects of transferring these patients to another ventilator, the Nippy (Friday Medical, Herne Hill, UK).

\section{Methods}

On the Monnal $\mathrm{D}$ the minute volume is preset. It operates in the assist/control mode with pressure triggering from expiration to inspiration. The maximum inspiratory pressure is approximately $120 \mathrm{~cm} \mathrm{H}_{2} \mathrm{O}$ and the maximum minute volume $20 \mathrm{l} / \mathrm{min}$. On the Nippy the peak inspiratory pressure is preset along with the inspiratory and maximum expiratory time. The maximum inspiratory pressure is approximately $32 \mathrm{~cm} \mathrm{H}_{2} \mathrm{O}$ and the maximum minute volume about $40 \mathrm{l} / \mathrm{min}$.

The records of all patients on long term NIPPV transferred from the Monnal D to the Nippy ventilator were examined. Patients who changed ventilators during an acute intercurrent illness were excluded. Ten patients (seven women) were identified who had initially responded well to treatment on the Monnal D but after an interval had developed recurrent symptoms of ventilatory failure or poor sleep and deteriorating overnight oximetry (mean arterial oxygen saturation $\left.\left(\mathrm{SaO}_{2}\right)<90 \%\right)$ or daytime arterial blood gas tensions $\left(\mathrm{PaCO}_{2}>7 \mathrm{kPa}\right.$ or $\mathrm{PaO}_{2}<8 \mathrm{kPa}$ ). In each case these features had been present for at least four weeks and had not responded to changes in the settings of the Monnal D (including timing and minute volume), attention to the mask fit, or to changes in medical treatment.

Details at initial referral ( $\mathrm{t} 0$ ) were recorded for age, diagnosis, daytime (between 09.00 and 17.00 hours) arterial blood gas tensions with the patient at rest breathing air, spirometric parameters measured using a dry spirometer (Vitalograph, Bucks, UK), and static lung volumes measured by helium dilution (PK Morgan 
Table 1 Age, diagnosis, and results of pulmonary function tests for the 10 patients transferred from the Monnal D to the Nippy ventilator

\begin{tabular}{lllllllll}
\hline $\begin{array}{l}\text { Patient } \\
\text { no. }\end{array}$ & $\begin{array}{l}\text { Age } \\
\text { (years) }\end{array}$ & Diagnosis & $\begin{array}{l}F E V_{1} \\
\text { (l) }\end{array}$ & $\begin{array}{l}F E V_{1} \\
\text { (\% predicted) }\end{array}$ & $\begin{array}{l}F V C \\
\text { (l) }\end{array}$ & $\begin{array}{l}F V C \\
\text { (\% predicted) }\end{array}$ & $\begin{array}{l}R V \\
\text { (l) }\end{array}$ & $\begin{array}{l}T L C \\
\text { (l) }\end{array}$ \\
\hline 1 & 70 & Pleural thickening & 0.64 & 32 & 0.74 & 30 & 1.47 & 2.2 \\
2 & 52 & TB spine, kyphosis & 0.28 & 12 & 0.37 & 14 & 0.6 & 1 \\
3 & 47 & Idiopathic scoliosis & 0.42 & 20 & 0.63 & 25 & 0.76 & 1.4 \\
4 & 62 & TB, PNC, pneumonectomy & 0.34 & 20 & 0.54 & 26 & 0.78 & 1.2 \\
5 & 66 & TB, thoracoplasty & 0.68 & 16 & 1.25 & 26 & 0.6 & 1.9 \\
6 & 63 & COPD & 0.6 & 24 & 1.55 & 77 & 3.5 & 5 \\
7 & 60 & COPD, TB & 0.7 & 30 & 1.35 & 50 & 3.22 & 4.6 \\
8 & 47 & Previous poliomyelitis & 0.51 & 17 & 0.66 & 18 & 0.88 & 1.5 \\
9 & 70 & Previous poliomyelitis & 0.7 & 30 & 1.25 & 42 & 2.09 & 3.3 \\
10 & 60 & Previous poliomyelitis & 0.9 & 39 & 1.4 & 57 & 1.03 & 2.4
\end{tabular}

$\mathrm{FEV}_{1}=$ forced expiratory volume in one second $\mathrm{FVC}=$ forced vital capacity; $\mathrm{RV}=$ residual volume; TLC = total lung capacity; $\mathrm{TB}=$ previous tuberculosis; $\mathrm{PNC}=$ phrenic nerve crush; $\mathrm{COPD}=$ chronic obstructive pulmonary disease.

Table 2 Mean (SD) results of arterial blood gas tension measurements and overnight oximetry

\begin{tabular}{|c|c|c|c|c|}
\hline & to & $t 1$ & $t 2$ & $t 3$ \\
\hline $\mathrm{PaO}_{2}(\mathrm{kPa})$ & $6.1 \quad(1.79)$ & $8.6(0.85)^{*}$ & $7.0 \quad(1.77)^{*}$ & $8.9(1.27)^{* *}$ \\
\hline $\mathrm{PaCO}_{2}(\mathrm{kPa})$ & $9.6 \quad(3.28)$ & $6.0(1.23)^{*}$ & $7.4 \quad(1.31)^{*}$ & $6.9(0.45) *$ \\
\hline Mean overnight $\mathrm{SaO}_{2}(\%)$ & $76 \quad(10.5)$ & $92 \quad(2.3)^{* *}$ & $86 \quad$ (8.6) NS & $93(2.1)^{*}$ \\
\hline Minimum overnight $\mathrm{SaO}_{2}(\%)$ & $54 \quad(14.4)$ & $79 \quad(4.2)^{* *}$ & $(14.6)^{*}$ & $83(4.6)^{*}$ \\
\hline
\end{tabular}

$\mathrm{t} 0=$ pretreatment; $\mathrm{t} 1=12$ weeks after initiation of NIPPV with the Monnal D ventilator; $\mathrm{t} 2=$ last admission before changing to the Nippy ventilator; $\mathrm{t} 3=12$ weeks after changing to the Nippy ventilator; $\mathrm{PaO}_{2}, \mathrm{PaCO}_{2}=$ arterial oxygen and carbon dioxide tensions; $\mathrm{SaO}_{2}=$ arterial oxygen saturation.

Statistical comparisons are made between pairs of results from $\mathrm{t} 0$ and $\mathrm{t} 1, \mathrm{t} 1$ and $\mathrm{t} 2, \mathrm{t} 2$ and $\mathrm{t} 3$ where $* \mathrm{p}<0.05, * * \mathrm{p}<0.01, \mathrm{NS}=$ non-significant.

Ltd, Kent, UK). The results of the spirometric tests were expressed as percentages of predicted values using arm span if spinal deformity was present. The pretreatment $\mathrm{SaO}_{2}$ had been recorded overnight using a Biox 3700 pulse oximeter (Ohmeda Herts, UK) and a chart recorder. The minimum $\mathrm{SaO}_{2}$ level was measured and the mean overnight value estimated. The daytime arterial blood gas tensions and overnight oximetry traces were also reviewed at 12 weeks after starting NIPPV with the Monnal D ( $\mathrm{t} 1$ ), at the last admission before changing to the Nippy (t2), and at 12 weeks after changing to the Nippy ( $\mathrm{t} 3$ ).

Statistical analyses were performed using the SPSS package (SPSS Inc, Chicago, USA). Paired $t$ tests were used for all comparisons and results of $p<0.05$ were accepted as significant.

\section{Results}

The mean (SD) age at t0 was 59.6 (8.39) years. All of the patients were symptomatic with increasing dyspnoea and disrupted sleep or daytime somnolence. Details of the diagnoses and pulmonary function tests at t0 are presented in table 1 . All of the patients had hypercapnic ventilatory failure at the time of referral with a $\mathrm{PaCO}_{2}$ of $>7.5 \mathrm{kPa}$ and were commenced on NIPPV, without additional oxygen, using the Monnal D ventilator. The mean preset minute volume was $15.8(1.72) 1 / \mathrm{min}$. At $t 1$ all of the patients reported a symptomatic benefit and daytime arterial blood gas tensions and the overnight oximetry measurements were significantly improved (table 2 ).

After varying periods of follow up the patients reported a return of their symptoms and daytime arterial blood gas tensions and/or overnight oximetry had deteriorated ( $\mathrm{t} 2$ in table 2 ). The patients were transferred to the Nippy ventilator after a mean (SD) period of 118 (69) weeks from the initiation of NIPPV. At $\mathrm{t} 3$ all of the measures of ventilation had once again improved (table 2). The mean period of follow up on the Nippy is now 59 (26.9) weeks. Eight of the patients have had more than one follow up admission. Only the patient with pleural thickening has deteriorated again, after a period of about 30 weeks, with radiological evidence for progression of the pleural disease.

\section{Discussion}

In the largest reported series of patients on NIPPV all were treated with the Monnal D ventilator and about $30 \%$ of these patients died or were converted to tracheostomy ventilation within two years of follow up. ${ }^{1}$ We have reported 10 patients from a population of 112 who deteriorated after an interval on NIPPV with the Monnal D. Changing to the Nippy ventilator improved their symptoms, daytime arterial blood gas tensions, and overnight oximetry. Pressure preset ventilators like the Nippy are now increasingly being used for NIPPV and it has been argued that they have different advantages and limitations from volume preset ventilators. ${ }^{23}$ Investigations with awake subjects ${ }^{34}$ have not shown such differences but the response to a change of ventilator which we have shown does indicate that limitations in the operating characteristics of the Monnal D compared with the Nippy are clinically important.

Secondary failure of treatment has been previously reported in patients started on negative pressure ventilation ${ }^{5}$ and has been attributed to progression of the underlying disorder. ${ }^{6}$ It seems unlikely that secondary failure on the Monnal D was due to a steady increase in respiratory impedance since the ventilator should compensate for this through an increase in airway pressure. In addition, the maximum pressure generated by the Nippy ventilator is less than that of the Monnal D, so changing 
the ventilator would not have produced the observed improvements.

Since the minute volume is preset on the Monnal D it cannot respond appropriately to an increase in patient effort. The patient may increase respiratory frequency by triggering the Monnal D, but tidal volume (VT) will fall, increasing the ratio of dead space to VT and decreasing alveolar ventilation. In contrast, each patient initiated breath from the Nippy ventilator will trigger the same inspiratory pressure so that minute volume will increase. This is further increased if patient effort continues through the inspiratory cycle of the Nippy when the negative intrapleural pressure generated by the patient sums with the positive mask pressure to increase VT. ${ }^{2}$

The Nippy can also compensate for variable leaks by increasing flow to maintain the preset pressure while the Monnal D cannot. Leaks around the mask or from the mouth are common with NIPPV and may lead to intermittent treatment failure. ${ }^{7}$ If the frequency or size of leaks had increased this might explain secondary failure in our patients on the Monnal $\mathrm{D}$ ventilator and the improvement on changing to the Nippy.

We have shown for the first time that patients successfully started on NIPPV with a minute volume preset ventilator, the Monnal D, may deteriorate after an interval and that their symptoms, daytime arterial blood gas tensions, and overnight oximetry can be improved again by changing to a pressure preset ventilator, the Nippy. Further work is required to elucidate the underlying mechanisms but our results do show that regular follow up is necessary in the management of patients started on NIPPV since their treatment requirements may change and appropriate intervention can reverse a secondary decline in ventilatory status.

1 Leger P, Bedicam JM, Cornette A, Reybet-Degat O, Langevin $\mathrm{B}$, Polu JM, et al. Nasal intermittent positive pressure ventilation. Long-term follow-up in patients with severe ventilation. Long-term follow-up in patients with severe
chronic respiratory insufficiency. Chest 1994;105:100-5.

2 Younes $M$. Proportional assist ventilation and pressure support ventilation: similarities and differences. Intensive Care port ventilation: similarities and

3 Elliott MW, Aquilina R, Green M, Moxham J, Simonds AK. A comparison of different modes of noninvasive ventilatory support: effects on ventilation and inspiratory muscle effort. Anaesthesia 1994;49:279-83.

4 Meecham Jones DJ, Wedzicha JA. Comparison of pressure preset and volume preset nasal ventilator systems in stable chronic respiratory failure. Eur Respir f 1993;6:1060-4.

5 Bach JR, Penek J. Obstructive sleep apnea complicating negative-pressure ventilatory support in patients with chronic paralytic/restrictive ventilatory dysfunction. Chest 1991;99;1386-93.

6 Bach JR, Alba AS, Bohatiuk G, Saporito L, Lee M. Mouth intermittent positive pressure ventilation in the management of post polio respiratory insufficiency. Chest 1987; 91:859-64.

7 Bach JR, Alba AS. Management of chronic alveolar hypoventilation by nasal ventilation. Chest 1990;97:52-7. 